freah looking young woman, and had a lively, intelligent appearance, which is contrary to what is usually stated as chrracteristic of the class. She said that she had taken a drachm of solid opium half an hour previous to her visit, in the presence of Mr. Brown, a respectable chemist and druggist in the neighbourhood. She mentioned that she had been in the habit of taking opium for six years, and that she had commenced the practice whilst suffering from an abscess in the side. She assured me that opium does not cause her to have any feelings of exhilaration or excitement. The effects last about twenty-four hours, after which she is obliged to repeat the dose. She has made sereral attempts to break the habit, but has given up the idea, owing to the superrention of diarrhoea on its discontinuance. When the effects of the opium begin to pass off, she feels pain in the back and limbs like rheumatism, or a soreness, as if she had been beaten, together with lowness of spirits and prostration of strength. These are again relieved by opium.

She wished me to prescribe for the diarrhoea-which I did; but I cannot say with what success. She thought that it would be exceedingly difficult to abandon opium-eatingmuch more so than spirit-drinking. She feels sure that she should not have resolution to give it up at once.

In a conversation which I subsequently had with $M r$. Brown, he told me that, when first she came to his shop to purchase her drachm of opium, he cautioned her as to the potency of the drug, and told her that she was probably mistaken as to the quantity she intended to take. In reply to this, she requested to be shown the weights he was in the habit of using, and immediately picked out the drachm weight from the rest of the weights on the counter, as an evidence of her familiarity with the quantity. He then suggested that it was possible that the opium she had formerly taken was not pure opium, but adulterated (as, at many of the inferior shops, it is mixed with chocolate or other harmless ingredients). She then requested to see his opium, and readily selected the best specimen he had. He opium, and readilyence in her, and she swallowed a drachm of opium in his presence. Since this time she has called repeatedly, and taken the same dose. She says she has had no children since she began taking the opium, and attributes this sterility to the habit. I may mention that the pupils of the eyes were not contracted as is common with those who are under the narcotic influence. Having taken her full dose of opium, she feels no desire to increase its effects by additional quantities.

Small as are these accessions to our knowledge on the subject, they may not be unacceptable to the psychological or toxicological inquirer.

\section{CASE OF MALFORMATION OF THE DUODENUM.}

\section{By Crosby Leonard, Esq.}

[Read bejore the Bath and Bristol Branch, Sept. 25th, 1856.]

Euzaветн HizL, aged 43, was confined of her twelfth child on May 15th, 1855. Mr. Cooper, a medical pupil, attended her. The child, a female, was apparently mature, but small; it constantly vomited everything given; it gradually sank, and died on May 20th, a hundred and seren hours after birth. It had a small evacuation per anum, and romited a little bloody fluid just before death.

I was present at the post mortern examination, on May 22nd. The child was very puny and shrunken in appearance. On opening the abdomen, the stomach was seen much distended with flatus. The commencement of the duodenum was enormously enlarged, of a globular shape, four and a quarter inches in circumference, the pylorus forming marked constriction between it and the stomach. No outlet existed inferiorly. The small and large intestines were of normal size, the small intestine gradually tapering superiorly, and terminating about one-third of an inch from the disteuded duodenum, to which it was connected by cellular tissue only. The gall and pancreatic ducts opened into the tapering upper extremity of the small intestines. The stomach contained some brownish fluid, mixed with small clots of blood. The large intestine was filled with meconium, the small intestines being nearly empty. All the other viscera were normal.

\section{Assoitiation attedical cournal.}

SATURDAY, OCTOBER 11TH, 1856.

\section{THE DRAINAGE OF THE METROPOLIS.}

THE question of the drainage of the metropolis is the great sanitary question of the day. We need not, therefore, apologise for commenting upon the discussions which have lately taken place in the Metropolitan Board of Works relative to the best manner of accomplishing that all important object. For years this grand proposal has been ventilated; the skill of engineers innumerable has been' taxed to produce plan after plan; a Board, expressly appointed to carry out the work, has been hopelessly broken up by its inability to grapple with the question: one and all, they battled for the use of the Thames as their main outlet, and one and all their schemes have been trampled upon as so much waste paper by the public press, which will not on any terms allow the metropolitan river to be so befouled. This very determination to keep the river pure has found a voice in the very Act of Parliament which constituted the new Board of Works. The 135th section of that Act expressly states, "that such Boards shall make such sewers and works as they may think necessary for preventing all or any part of the sewage from flowing or passing into the Thames in or near the metropolis, and shall cause such sewers and works to be completed on or before the 31st day of December, 1860." After such explicit directions as these, backed by the opinion of the vast majority of scientific men, we should have imagined that the new Board would have resolutely set about carrying out the intentions of the legislature, by maturing such a scheme as would at once have been worthy of the metropolis and calculated to fulfil all the conditions necessary to insure the purity of the river which runs through the largest European capital. But it seems that they have expressly set themselves to work to defy the Act of Parliament, and to violate every principle of common sense. Their engineer proposes to them four plans for the drainage of the metropolis, and not one of these is calculated to fulfil the intention of the Act, or to comply with the general wish. Nevertheless, they have all been grarely discussed by the "Metropolitan Parliament", as the Board is called; and the most objectionable of the four, which deliberately proposes to throw the whole sewage of 2,500,000 people into Barking Creek, within sight almost of the capital, has receired its approval, and been forwarded to Sir B. Hall, who of course very properly returned it as not calculated to accomplish the all important purpose-the purification at one and the 